\title{
Penilaian Kondisi Jalan Poros Sabbang Selatan Menggunakan Metode Surface Distress Index
}

\author{
Dewi Artika Sari ${ }^{1}$, Afdal Kisman² \\ ${ }^{1,2}$ Universitas Andi Djemma Palopo, JL.Tandipau No.5 Palopo, Indonesia \\ E-mail: ${ }^{1}$ tekniksipil_unanda@yahoo.com, ${ }^{2}$ dewiartikasari946@gmail.com,3afdhalkisman97@gmail.com
}

\section{Kata Kunci}

Kondisi jalan, tingkat kerusakan, penanganan, Surface Distress Index (SDI)

\begin{abstract}
Abstrak
Prasarana jalan jika terbebani volume lalu lintas yang tinggi dan berulang-ulang akan menyebabkan terjadinya penurunan kualitas jalan sehingga dapat mempengaruhi keamanan, kenyamanan dan kelancaran dalam berlalu lintas. Untuk menjaga agar tidak terjadi penurunan kondisi khususnya pada jalan poros Kecamatan Sabbang Selatan Kabupaten Luwu Utara tepatnya di jalan Padang Sarre, Buntu Terpedo sampai jalan Dandang sepanjang 4 km perlu adanya penanganan. Maka perlu dilakukan penelitian awal terhadap kondisi permukaan jalan dengan melakukan survei secara visual dengan cara menganalisa kerusakan berdasarkan jenis dan tingkat kerusakannya. Tujuan penelitian yaitu menilai kondisi perkerasan danpenanganan sesuai kondisi permukaan jalan. Penelitian ini menggunakan system penilaian kondisi perkerasan menurut Bina Marga dengan perhitungan Surface Distress Index (SDI) untuk jalan beraspal. Dari hasil penelitian di dapatkan penilaian untuk jenis kerusakan permukaan jalan pada ruas kanan yaitu retak pinggir $1,183 \%$, lubang $0,031 \%$, amblas $0,054 \%$, retak kulit buaya 3,271\%, retak kotak-kotak 3,222\%, tambalan $0,033 \%$ dan pengelupasan butir $0,013 \%$. Sedangkan untuk ruas kiri yaitu retak pinggir $0,035 \%$, lubang $0,051 \%$, amblas $0,000 \%$, retak kulit buaya $0,130 \%$, retak kotak-kotak 2,351\%, tambalan $0,000 \%$ dan pengelupasan butir $0,150 \%$. Kondisi perkerasan jalan yang menjadi objek penelitian sepanjang $4 \mathrm{~km}$ yaitu $85 \%$ baik, $0 \%$ sedang, $15 \%$ rusak ringan, $0 \%$ rusakberat.
\end{abstract}

\begin{abstract}
Road infrastructure if it is burdened by high and repetitive traffic volumes will cause a decrease in road quality so that it can affect safety, comfort and smoothness in traffic. To prevent deterioration in conditions, especially on the axis road of South Sabbang District, North Luwu Regency, precisely on Padang Sarre road, Buntu Terpedo to Dandang road

Keyword

road conditions, level of damage, handling, Surface Distress Index (SDI) along $4 \mathrm{~km}$, it needs handling. So it is necessary to conduct an initial research on road surface conditions by conducting a visual survey by analyzing the damage based on the type and level of damage. The research objective was to assess pavement conditions and handling according to road surface conditions. This study uses a pavement condition assessment system according to Bina Marga with the calculation of the Surface Distress Index (SDI) for asphalt roads. From the research results obtained an assessment for the type of road surface damage on the right side, namely edge cracks $1.183 \%$, holes $0.031 \%$, collapse $0.054 \%$, crocodile skin cracks $3.271 \%$, checkered cracks $3.222 \%, 0.033 \%$ patches and $0.013 \%$ peeling grains. Whereas for the left section, the edges cracked $0.035 \%$, holes $0.051 \%$, collapsed $0.000 \%$, crocodile skin cracks $0.130 \%$, checkered cracks $2.351 \%$, fillings $0.000 \%$ and peeling $0.150 \%$. The condition of the pavement which is the object of the research along $4 \mathrm{~km}$ is $85 \%$ good, $0 \%$ moderate, $15 \%$ lightly damaged, $0 \%$ heavily damaged.
\end{abstract}

\section{PENDAHULUAN}

Jalan merupakan prasarana transportasi yang memiliki peran penting dalam mendukung perkembangan sektor ekonomi, sosial budaya, pertahanan keamanan dan berbagai sektor lainnya. Prasarana jalan yang baik dapat mendukung kelancaran distribusi barang dan jasa (Humang, 2018). Prasarana jalan yang baik adalah jalan yang mempunyai konektifitas, aksesibilitas dan kondisi perkerasan yang baik (Chalid, 2016). Kerusakan jalan yang ada sering diakibatkan oleh faktor alam ataupun faktor manusia. Apabila terjadi kerusakan dalam kondisi ringan, maka perlu adanya pemeliharaan sehingga tidak terjadi kerusakan yang lebih parah dan membutuhkan biaya yang lebih mahal.

Penilaian kerusakan jalan dapat dilakukan dengan metode Surface Distress Index yang dilakukan dengan menilai kondisi jalan diperoleh berdasarkan survei visual (Fakhri \& Dezfoulian, 2019). Kecamatan Sabbang 
Selatan Kabupaten Luwu Utara yang merupakan jalan yang menghubungkan Kabupaten Luwu Utara dengan Kabupaten Luwu. Kami memilih lokasi ini sebagai tempat penelitian karena kondisi jalan poros tersebut mengalami kerusakan seperti retak, lubang, dan lain- lain. Oleh sebab itu untuk menjaga kondisi perkerasan jalan sampai umur rencana maka harus dilakukan pemeliharaan maupun rehabilitasi.

Tujuan yang akan dicapai dalam penelitian ini adalah menilai kondisi perkerasan dan penanganan jalan poros Kecamatan Sabbang Selatan Kabupaten Luwu Utara menurut metode Surface DistressIndex.

Jalan adalah prasarana transportasi darat yang meliputi segala bagian jalan termasuk bangunan pelengkap dan perlengkapannya yang diperuntukkan bagi lalu lintas. Menurut UU no. 38 tahun 2004 klasifikasi jalan dibedakan menjadi 4 yaitu berdasarkan peruntukan, jaringan, fungsi dan status.

Konstruksi jalan (perkerasan) secara umum terdiri atas 3 lapisan utama yaitu : lapisan pondasi bawah (subbase course), lapisan pondasi atas (base course) lapisan permukaan atau surface course (Al Qadi et al, 2017). Jenis kerusakan yang terjadi pada suatu jalan dapat dikaji berdasarkan lapisan-lapisan konstruksi perkerasan jalan (Wang \& Wang, 2019). Lapisan permukaan perkerasan jalan merupakan lapisan yang langsung berhubungan dengan aktifitas kendaraan lalu lintas, dan di Indonesia sekitar 80\% ruas jalan masih menggunakan lapisan permukaan lentur yang terbuat dari material aspal. Perkerasan jalan mempunyai umur rencana tertentu sesuai dengan umur desain yang telah ditetapkan. Umur rencana yang digunakan dalam desain di Indonesia adalah 10 tahun untuk perkerasan lentur (Ragnoli et al, 2018). Selama masa layanan, perkerasan akan mengalami pembebanan berulang. Kondisi ini perlu diantisipasi dengan langkah- langkah pencegahan terutama dengan dilakukannya pemeliharaan jalan (Ahmad Tri Heriyanto, 2020). Perkerasan jalan adalah campuran agregat dan bahan ikat yang terletak di atas tanah dasar dengan pemadatan untuk melayani beban lalu lintas. Tujuan utama pembuatan struktur perkerasan jalan adalah untuk mengurangi tegangan atau tekanan akibat beban roda sehingga mencapai tingkat nilai yang dapat diterima oleh tanah yang menyokong beban tersebut (Mubaraki \& Sallam, 2020).

Perkerasan lentur (flexibel Pavement), yaitu suatu jenis kerusakan yang menggunakan aspal sebagai bahan pengikat dan mempunyai sifat lentur dimana setelah pembenahan berlangsung perkerasan akan seperti semula. Menurut Departemen Pekerjaan Umum (1987) yang dimaksud dengan perkerasan lentur adalah perkerasan yang pada umumnya menggunakan bahan campuran beraspal sebagai pelapis permukaan serta bahan berbutir sebagai lapisan bawahnya. Perkerasan lentur harus mempunyai ketahanan pavement yang dinyatakan sebagai Modulus of Resiliance (Karami, 2018). Modulus of Resiliance yaitu ukuran kemampuan material untuk menyerap energi dari luar tempat terjadinyakerusakan.

Pada struktur perkerasan jalan, beban lalu lintas didistribusikan ke tanah dasar secara berjenjang dan berlapis (layer system) (Arianto \& Suprapto, 2018). Dengan sistem ini beban lalu lintas didistribusikan dari lapisan atas ke lapisan di bawahnya (Sukirman, 1992). Konstruksi perkerasan jalan lentur terdiri dari lapisanlapisan yang diletakkan diatas tanah yang telah dipadatkan. Lapisan-lapisan tersebut berfungsi menerima beban lalu lintas dan menyebarkannya ke lapisan di bawahnya. (Gupta et al, 2018)

Salah satu sistem penilaian kondisi perkerasan jalan berdasarkan dengan pengamatan visual dan dapat digunakan sebagai acuan dalam menentukan usaha pemeliharaan adalah metode Surface Distress Index yang dikembangkan oleh direktorat jenderal Bina Marga. Metode Surface Distress Index adalah pemeriksaan secara visual dengan data parameter luas total keretakan,lebar rata-rata keretakan, jumlah lubang dan kedalaman bekas roda kendaraan. Hasil pemeriksaan terhadap parameter-parameter tersebut kemudian dihitung menggunakan standar penilaian yang ditetapkan oleh Bina Marga.

Nilai Surface Distress Index yang diperoleh hasil survey dapat dijadikan acuan dalam penentuan penanganan jalan yaitu berupa nilai dari tiap jenis kerusakan yang diidentifikasi, sehingga untuk menentukan penilaian kondisi jalan dilakukan dengan cara menjumlahkan seluruh nilai perkerasan yang ada (Rosada et al 2019). Semakin besar angka kerusakan kumulatif akan semakin besar pula nilai kondisi jalan, yang diartikan jalan tersebut memiliki kondisi yang buruk sehingga membutuhkan penangan yang lebih baik.Kriteria kondisi jalan dari data Surface Distress Index dapat di lihat pada tabel di bawah ini.

\begin{tabular}{|c|c|}
\hline KONDISI JALAN & NILAI SURFACE DISTRESS INDEX \\
\hline BAIK & $<50$ \\
\hline SEDANG & $50-100$ \\
\hline RUSAK RINGAN & $100-150$ \\
\hline RUSAK BERAT & $>150$ \\
\hline
\end{tabular}




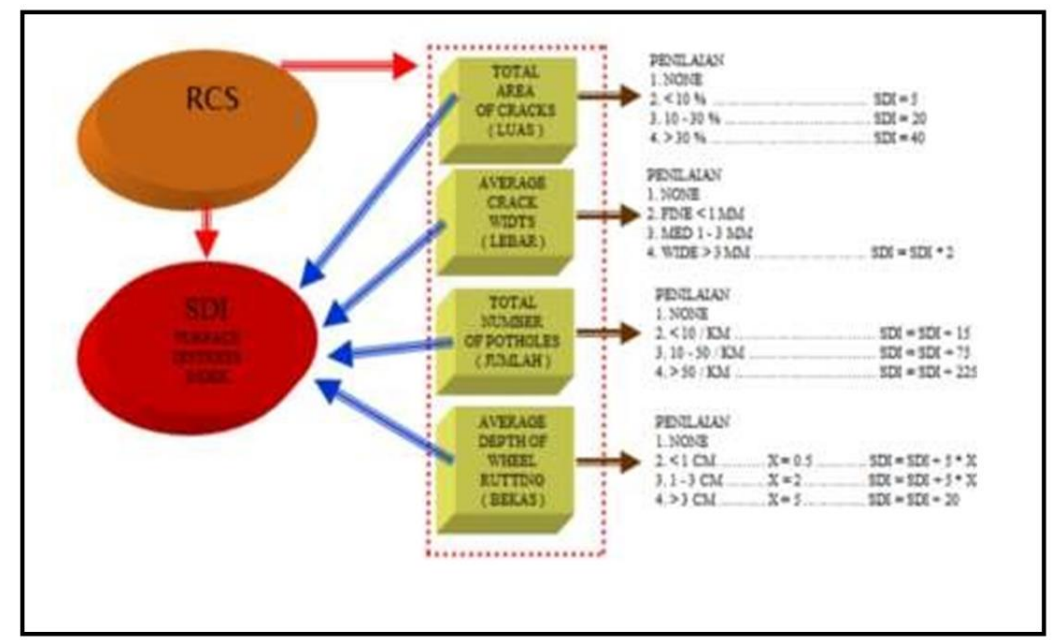

Gambar 1. Standar Penilaian Metode Surface Distress Index

Jenis-jenis kerusakan yang terjadi pada perkerasan jalan akibat beberapa factor kerusakan berdasarkan Manual Pemeliharaan Direktorat Jendral Bina Marga No. 03/MN/B/1983, kerusakan jalan dapat dibedakan kedalam 19 (Sembilan belas) jenis kerusakan yaitu ; (a) Retak Kulit Buaya (AlligatorCracking) (b) Kegemukan(Bleeding), (c) Retak Kotak-kotak (BlockCracking), (d) Cekungan (Blumps andSags), (e) Keriting(Corrugation), (f) Amblas(Depression), (g) Retak Pinggir (EdgeRacking), (h) Retak Sambung (Join ReflectionCracking), (i) Pinggiran Jalan Turun Vertikal (Lane/Shoulder DropOff), (i) Retak Memanjang/ Melintang (Longitudinal/ TransverseCracking), (j) Tambalan (Patching and Utility CutPatching), (k) Pengausan Agregat (PolishedAggregate), (1) Lubang (Patholes), (m) Rusak Perpotongan Rel (RailroadCrossing), (n) Alur(Rutting), (o) Sungkar (Shoving), (q) Patah Slip (SlippageCracking), (r) Menggembung Jembul (Swell), (s) Pelepasan Butir (Weathering/Raveling)

\section{METODOLOGI PENELITIAN}

Jenis penelitan yang digunakan yaitu jenis penelitian kuantitatif dimana penelitian yang lebih menuju pada aspek pengukuran secara objektif. Pada penelitian ini dilakukan survey secara langsung di lapangan dan mengklasifikasikan kerusakan perkerasan jalan berdasarkan jenis dan tingkat kerusakannya. Penelitian ini menggunakan sistem analisa penilaian kondisi perkerasan jalan menurut Surface Distress Index (yahya et al, 2019).

Langkah awal dalam melakukan penelitian adalah dengan terlebih dahulu mengetahui latar belakang dari daerah yang menjadi objek dari penelitian sehingga didapatkan suatu rumusan permasalahan yang ada untuk selanjutnya dijadikan tujuan penelitian. Setelah itu di kumpulkan berbagai macam data yang diperlukan untuk melakukan penelitian yaitu data primer.

Metode yang digunakan dalam penelitian ini adalah survei. Survei adalah metode penelitian yang sumber data dan informasi utamanya diperoleh dari pengamatan secara langsung dilapangan. Pengambilan data dilakukan setiap 50 meter sepanjang $4 \mathrm{~km}$ pada setiap ruas dengan metode yang digunakan yaitu Surface DistressIndex.

Pada penelitian ini, data primer yang digunakan adalah hasil observasi atau penelitian langsung di lokasi penelitian. Dimana pengambilan data kerusakan jalan dilakukan setiap 50 meter sepanjang $4 \mathrm{~km}$ pada setiap ruas. Serta terdapat beberapa data sekunder diantaranya yaitu standar penilaian dan tabel kondisi jalan metode Surface Distress Index (SDI) yang ditetapkan oleh Bina Marga.

Teknik analisis data visual dengan menggunakan metode Surface Distress Index disajikan pada perhitungan kondisi fungsional jalan dengan menentukan nilai Surface Distress Index (SDI) suatu segmen jalan. Langkah awal yaitu dengan menetapkan nilai $\mathrm{SDI}_{1}$ awal berdasarkan luas retak kemudian menetapkan $\mathrm{SDI}_{2}$ berdasarkan lebar rata-rata retak. Langkah selanjutnya yaitu menetapkan nilai $\mathrm{SDI}_{3}$ berdasarkan jumlah lubang serta menetapkan $\mathrm{SDI}_{4}$ berdasarkan bekas roda kendaraan. 


\section{HASIL DAN PEMBAHASAN}

Berdasarkan permasalahan dan metode penelitian yang telah dikemukakan, maka diperoleh hasil presentase kerusakan jalan, data visual dengan menggunakan metode SDI yang selanjutnya dilakukan pembahasan sehingga dapat diidentifikasi kondisi kerusakan pada jalan Padang Sarre Buntu Torpedo sampai jalan Dandang, sepanjang $4 \mathrm{~km}$.

\section{A. Tingkat Kerusakan Jalan}

Dari hasil pengambilan data secara langsung dilokasi penelitian. Maka diperoleh hasil presentase kerusakan jalan seperti pada tabel dibawah.

\begin{tabular}{|c|l|c|c|}
\hline \multirow{2}{*}{ No. } & \multirow{2}{*}{ JENIS KERUSAKAN } & \multicolumn{2}{|c|}{ LUAS TOTAL KERUSAKAN (\%) } \\
\cline { 3 - 4 } & & RUAS KANAN & RUAS KIRI \\
\hline 1 & Retak Pinggir & 1,183 & 0,035 \\
\hline 2 & Lubang & 0,031 & 0,051 \\
\hline 3 & Amblas & 0,054 & 0,000 \\
\hline 4 & Retak Buaya & 0,271 & 0,130 \\
\hline 5 & Retak Kotak-Kotak & 3,222 & 2,351 \\
\hline 6 & Tambalan & 0,033 & 0,000 \\
\hline 7 & Pengelupasan Butir & 0,013 & 0,150 \\
\hline \multicolumn{2}{|c|}{ TOTAL } & $\mathbf{4 , 8 0 8}$ & $\mathbf{2 , 7 1 8}$ \\
\hline
\end{tabular}

Pada tabel presentase ruas kerusakan jalan dapat dilihat bahwa pada jalan Padang Sarre, Buntu Terpedo sampai Dandang tingkat kerusakan permukaan jalan ruas kanan dan ruas kiri kerusakan paling banyak yaitu retak kotak-kotak, dimana kerusakannya yaitu 3,222\% dan 2,351\%. Hal tersebut disebabkan oleh adanya gerakan vertikal atau horizontal di bawah lapisan tambahan sebagai akibat perubahan kadar air pada jenis tanah. Total luas presentase kerusakan pada lokasi penelitian yaitu 4,808\% di ruas kanan dan 2,718\% pada ruas kiri. Dapat dilihat pada Gambar 2 dan Gambar 3.

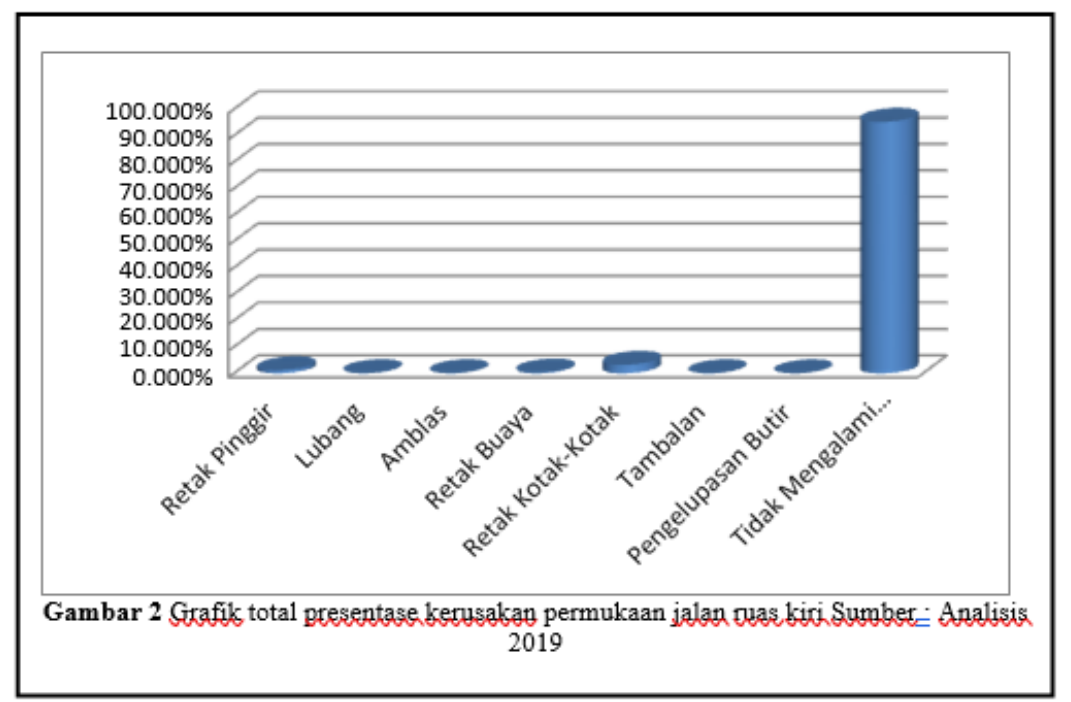




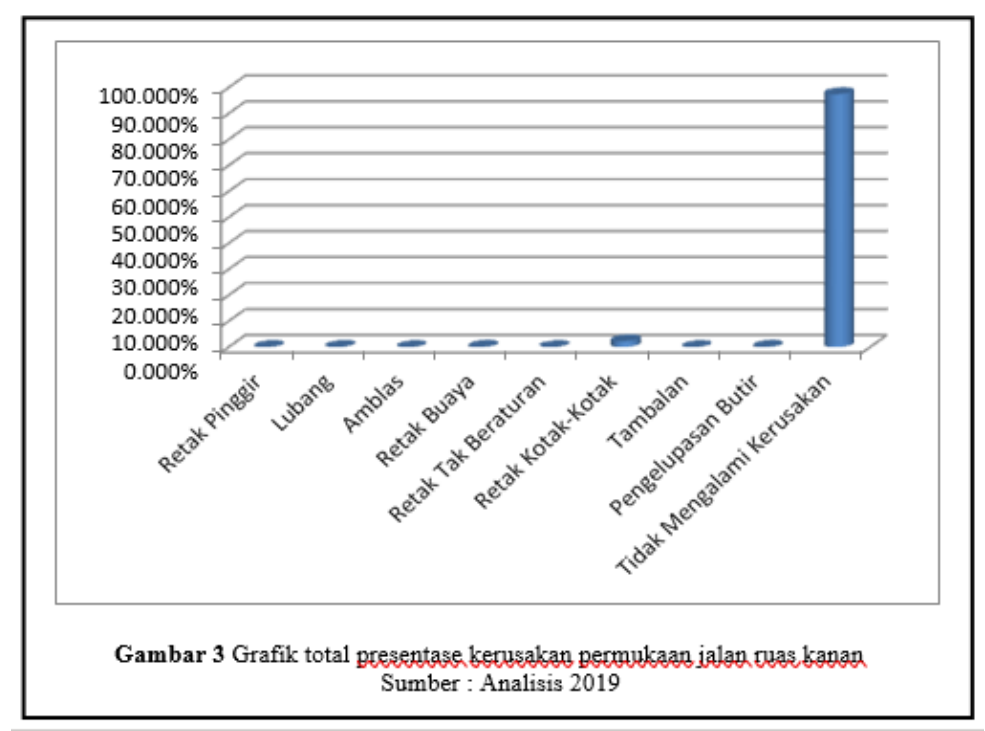

B. Hasil Analisis Data Visual Dengan MetodeSDI

Dari hasil penelitian dilapangan maka didapatkan hasil analisa seperti pada dibawah

\begin{tabular}{|c|c|c|c|c|c|c|c|}
\hline \multirow{3}{*}{ No. } & \multirow{3}{*}{$\begin{array}{c}\text { JENIS } \\
\text { KERUSAKAN }\end{array}$} & \multicolumn{6}{|c|}{ ANALISIS DATA SDI } \\
\hline & & \multicolumn{3}{|c|}{ RUAS KANAN } & \multicolumn{3}{|c|}{ RUAS KIRI } \\
\hline & & SDI1 & SDI2 & SDI4 & SDI1 & SDI2 & SDI4 \\
\hline 1 & Retak Pinggir & 5 & 10 & - & 5 & 10 & - \\
\hline 2 & Lubang & 5 & 10 & - & 5 & 10 & - \\
\hline 3 & Amblas & 5 & 10 & - & 5 & 10 & 95 \\
\hline 4 & Retak Buaya & 5 & 10 & - & 5 & 10 & - \\
\hline 5 & $\begin{array}{l}\text { Retak Kotak- } \\
\text { Kotak }\end{array}$ & 5 & 10 & - & 5 & 10 & - \\
\hline 6 & Tambalan & 5 & 10 & - & 5 & 10 & - \\
\hline 7 & $\begin{array}{l}\text { Pengelupasan } \\
\text { Butir }\end{array}$ & 5 & 10 & - & 5 & 10 & - \\
\hline \multicolumn{8}{|c|}{ Sumber : Analisis 2019} \\
\hline
\end{tabular}


Tabel 4 Analisis data visual (SDI3) dengan metode SDI

\begin{tabular}{|c|c|c|c|c|}
\hline \multirow{2}{*}{ Jarak (km) } & \multicolumn{2}{|c|}{ Jumlah Lubang } & \multicolumn{2}{c|}{ SDI3 = SDI2 + 75 } \\
\cline { 2 - 5 } & $\begin{array}{c}\text { RUAS } \\
\text { KANAN }\end{array}$ & $\begin{array}{c}\text { RUAS } \\
\text { KIRI }\end{array}$ & $\begin{array}{c}\text { RUAS } \\
\text { KANAN }\end{array}$ & $\begin{array}{c}\text { RUAS } \\
\text { KIRI }\end{array}$ \\
\hline 1 & 13 & 22 & 85 & 85 \\
\hline 2 & 12 & 16 & 85 & 85 \\
\hline 3 & 10 & 10 & 85 & 85 \\
\hline 4 & 16 & 13 & 85 & 85 \\
\hline \multicolumn{3}{|c|}{ Rata - Rata } & $\mathbf{8 5}$ & $\mathbf{8 5}$ \\
\hline
\end{tabular}

Sumber : Analisis 2019

Dari Tabel 3 dan Tabel 4 dapat dilihat bahwa nilai SDI1 pada jalan Padang Sarre Buntu Torpedo sampai jalan Dandang adalah 5. Dimana luas retak setiap kerusakan pada ruas kiri dan ruas kanan $<10 \%$ dari luas total jalan yang dilakukan penelitian. Nilai dari SDI2 adalah 10 karena berdasarkan lebar rata- rata retak $>3$ $\mathrm{mm}$ jadi nilai dari SDI $* 2$. Nilai SDI3 pada ruas kiri dan ruas kanan memiliki nilai yang sama 85 karena jumlah lubang atau jumlah kerusakan di lokasi penelitian yaitu $10-50 / \mathrm{Km}$. Pada ruas kanan tidak ada nilai SDI4 karena tidak terdapat bekas roda kendaraan, sedangkan pada ruas kiri terdapat bekas roda kendaraan dengan nilai SDI4 adalah 95, yang dimana kedalaman rutting $1-3 \mathrm{~cm}$ maka SDI4 $=$ SDI $3+5 * \mathrm{X}$, dengan nilai $\mathrm{X}$ yaitu2.

\section{Tingkat KerusakanJalan}

Penentuan kondisi jalan diperoleh berdasarkan nilai SDI. Dari nilai tersebut dapat menentukan kondisi jalan yaitu kondisi baik, sedang, rusak ringan maupun rusak berat setiap jarak interval 50 meter panjang jalan, dapat dilihat pada tabel 2 presentase kerusakan jalan, Gambar 4 dan Gambar 5

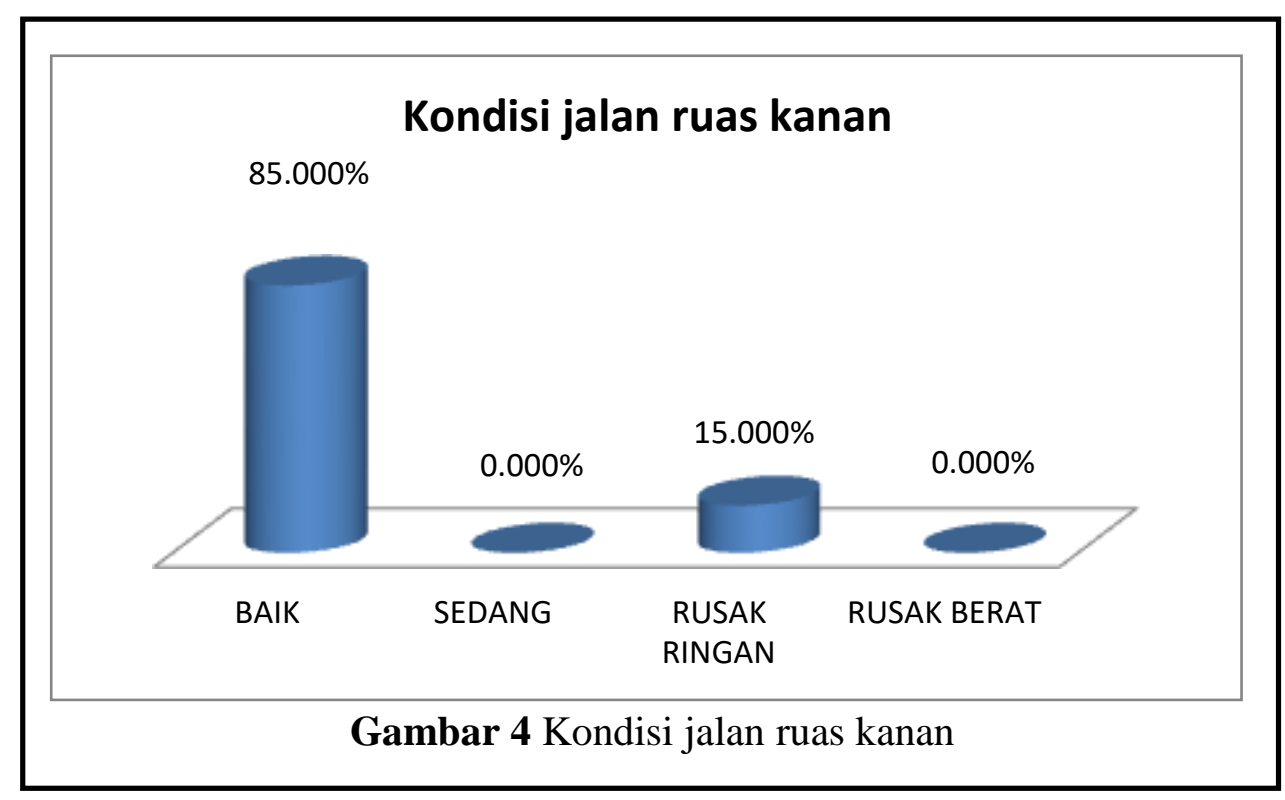




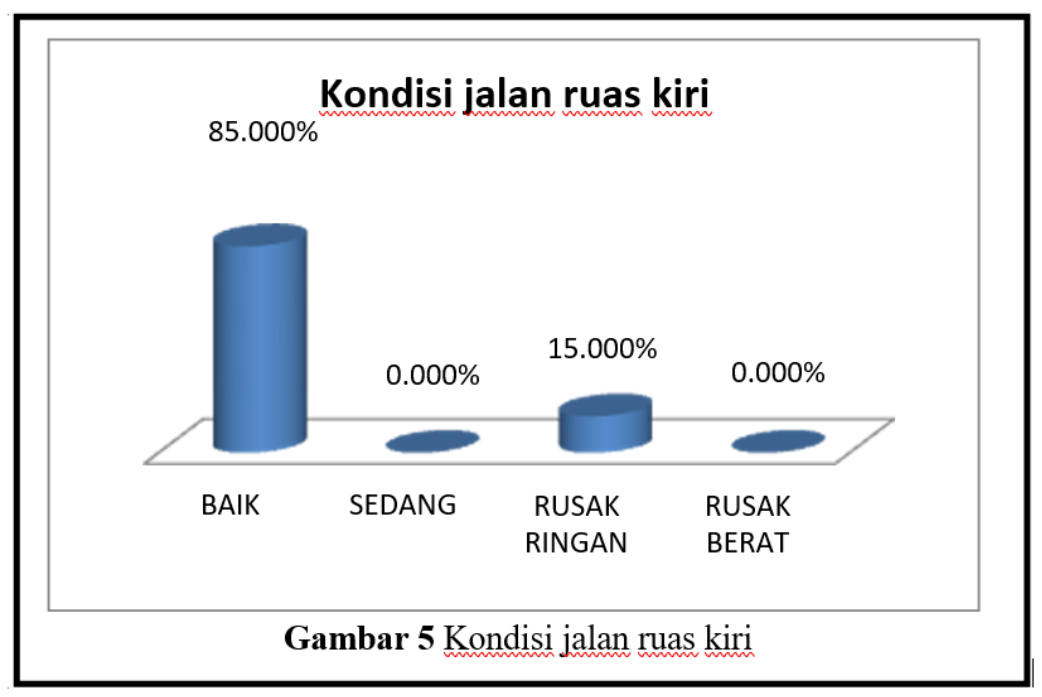

D. Jenis Kerusakan di Lokasi Penelitian

Hasil penelitian yang diperoleh adalah berupa data-data kondisi jalan dengan cara pengumpulan data survey visual yaitu kategori kerusakan jalan, ukuran dan presentase kerusakan jalan. Adapan kerusakan yang terdapat pada lokasi penelitian yaitu retak pinggir, lubang, amblas, retak kulit buaya, retak kotak-kotak, tambalan dan pengelupasan butir. Rata-rata penyebab dari kerusakan yaitu tidak adanya drainase, beban kendaraan yang melintas melebihi dengan apa yang direncanakan, penyusutan tanah, adanya air yang tergenang di lokasitersebut.

\section{E. Penanganan Kerusakan Jalan}

Kerusakan jalan memang menjadi salah satu masalah di Indonesia yang seringkali terjadi terutama dilokasi penelitian ini yaitu dijalan Padang Sarre, Buntu Torpedo sampai Dandang. Berikut adalah cara penanganan kerusakan di lokasi penelitian yaitu

1. Retak pinggir dengan cara jika bahu jalan tidak mendukung pinggir perkerasan, maka material yang buruk dibongkar dan digantikan dengan material baik yang dipadatkan, jika air menjadi faktor kerusakan, maka harus dibuatkandrainase.

2. Lubang dengan cara yaitu perbaikan permanen dilakukan dengan penambalan diseluruh kedalaman, perbaikan sementara dilakukan dengan membersihkan lubang dan mengisinya dengan campuran aspal dingin yang khusus untuktambalan.

3. Amblas dengan cara yaitu untuk area kerusakan yang besar, perbaikan dapat dilakukan dengan menambal permukaannya atau menambal pada seluruhkedalaman.

4. Retak kulit buaya dengan cara yaitu jika tingkat kerusakan ringan, pemeliharaan sementara seperti menutup dengan larutan penutup (slurry seal) atau penanganan permukaan yang lain. Penambalan dapat membantu sebelum perbaikan permanen dilakukan. Penutupan retakan dengan pengisi tidak begitu efektif untuk perbaikan retak kulitbuaya.

5. Retak kotak-kotak dengan cara yaitu retak dapat ditutup dengan larutan pengisi. Retak yang besar diisi dengan larutan emulsi aspal yang diikuti dengan penanganan permukaan atau larutanpengisi.

6. Tambalan dengan cara yaitu perbaikan atau penggantian tambalan diseluruh kedalaman untuk perbaikanpermanen.

7. Pengelupasan butir dengan cara penanganannya yaitu perawatan permukaan dengan menggunakan chip vcal atau slurryseal.

\section{KESIMPULAN}

Berdasarkan penyajian data dan analisis yang dilakukan terhadap perhitungan dan nilai SDI yang diperoleh pada penelitian, dapat disimpulkan bahwa kondisi perkerasan jalan yang diperoleh dari keseluruhan panjang jalan yang menjadi objek penelitian sepanjang $4 \mathrm{~km}$ yaitu $85 \%$ baik, $0 \%$ sedang, $15 \%$ rusak ringan, $0 \%$ rusak berat. Pada penelitian yang kami lakukan kondisi perkerasan jalan pada ruas kiri dan ruas kanansama.

\section{DAFTAR PUSTAKA}


Akhmad Tri Heriyanto. (2020). Penyandingan Surface Distress Index (Sdi) Dan International Roughness Index (Iri) Pada Identifikasi Kerusakan Jalan. (Studi Kasus: Jalan Nasional Ruas Simpang PenawarGedong Aji Baru Di Tulang Bawang, Lampung, Universitas Lampung, Bandar Lampung.

Al-Qadi, I. L., Wu, S., Lippert, D. L., Ozer, H., Barry, M. K., \& Safi, F. R. (2017). Impact Of High Recycled Mixed On Hma Overlay Crack Development Rate. Road Materials And Pavement Design, 18(Sup4), 311-327.

Arianto, T., \& Suprapto, M. (2018, March). Pavement Condition Assessment Using Iri From Roadroid And Surface Distress Index Method On National Road In Sumenep Regency. In Iop Conference Series: Materials Science And Engineering (Vol. 333, No. 1, P. 012091). Iop Publishing.

Chalid, N. I. (2016). Karakteristik Campuran Aspal Hrs-Base Menggunakan Agregat Kasar Batu Kapur Asal Tinoring. Pena Teknik: Jurnal Ilmiah Ilmu-Ilmu Teknik, 1(1), 81-94

Departemen Pekerjaan Umum (1987), Petunjuk Perencanaan Tebal Prekerasan Lentur Jalan Rsya Engan Metode Analisa Komponen,(Skbi-2.3.26).

Direktorat Bina Teknik. (2002). Survei Kondisi Jalan Beraspal Di Perkotaan. Direktorat Jendral Tata Perkotaan Dan Tata Pedesaan Departemen Pemukiman Dan Prasarana Wilayah. Jakarta

Direktorat Pembinaan Jalan Kota. (1990). Tata Cara Penyusunan Pemeliharaan Kota (No. 018/T/Bnkt/1990). Direktorat Jendral Bina Marga Departemen Pu. Jakarta

Fakhri, M., \& Dezfoulian, R. S. (2019). Pavement Structural Evaluation Based On Roughness And Surface Distress Survey Using Neural Network Model. Construction And Building Materials, 204, 768-780.

Gupta, P. K., \& Atri, P. (2018). Pavement Surface Distress Evaluation Using Pci. Int. J. For Res. In Appl. Sci. \& Eng. Technol.(Ijraset), 6(3), 2321-9653.

Hermani, W. T., Setyawan, A. (2013). Kondisi Kemantapan Jalan Berdasarkan Beban Lalu Lintas Dan Ketersediaan Dana Penanganan. Jurnal Teknik Sipil Magister Teknik Sipil Universitas Sebelas Maret, Vol. 1, Hlm 1-6.

Humang, W. P., \& Amrin, A. (2018). Peningkatan Akses Jalan Untuk Menunjang Distribusi Hasil Produksi Kota Terpadu Mandiri (Ktm) Air Terang Kabupaten Buol. Pena Teknik: Jurnal Ilmiah Ilmu-Ilmu Teknik, 1(2), 111-124.

Karami, M. (2018). Fatigue Performance Of Buton Rock Asphalt Modified Mixtures. International Journal Of Pavement Research And Technology.

Mubaraki, M., \& Sallam, H. (2020). The Most Effective Index For Pavement Management Of Urban Major Roads At A Network Level. Arabian Journal For Science And Engineering, 1-12.

Ragnoli, A., De Blasiis, M. R., \& Di Benedetto, A. (2018). Pavement Distress Detection Methods: A Review. Infrastructures, 3(4), 58.

Rosada, A., Arliansyah, J., \& Buchari, E. (2019, April). Evaluation Pavement Deteriorating Condition On Surface Distress Index (Sdi) Data Using Radial Basis Function Neural Networks (Rbfnn). In Journal Of Physics: Conference Series (Vol. 1198, No. 3, P. 032008). Iop Publishing.

Sukirman, S., (1992), Perkerasan Lentur Jalan Raya, Penerbit Nova, Bandung

Wang, H., \& Wang, Z. (2019). Deterministic And Probabilistic Life-Cycle Cost Analysis Of Pavement Overlays With Different Pre-Overlay Conditions. Road Materials And Pavement Design, 20(1), 58-73.

Yahya, R., Bin Aman, M. Y., Suraji, A., \& Halim, A. (2019, November). Analisis Kerusakan Jalan Menggunakan Metode Pavement Condition Index (Pci) Dan Surface Distress Indek (Sdi). In Conference On Innovation And Application Of Science And Technology (Ciastech) (Vol. 2, No. 1, Pp. 355-362). 